\section{Labelling laws for transgenic food come into effect}

Laura Nelson, London

Europe this week introduced stringent rules for the labelling of food that contains genetically modified organisms. But in most countries the labels will take months to appear - and questions remain about how they will be implemented.

The rules, which are imposed by the European Union and came into effect on 19 April, are intended to aid consumer acceptance of genetically modified food in Europe. They may help to defuse a US complaint to the World Trade Organization (WTO) that Europe is unfairly blocking imports of transgenic food.

Food containing more than $0.9 \%$ genetically modified ingredients must be clearly labelled as doing so, the rules say. If the ingredients are awaiting final approval as being safe to eat, that threshold falls to $0.5 \%$.

"This is the biggest piece of legislation in the food industry for 20 years," says Richard Werran, head of Cert ID, a firm based in Fairfield, Iowa, that is offering to test food for its transgenic content.

Britain, Germany and the Netherlands are expected to implement the regulations in stores within a few months, but other nations may take longer.

The rules require food to be tracked from its source through manufacture to the point of sale. Manufacturers and packagers will also have to test food directly for traces of genetically modified organisms. A network of laboratories set up and operated by the European Commission (EC) has developed a series of standard tests.

The Institute for Health and Consumer Protection, part of the EC's Joint Research Centre in Ispra, Italy, has led the development of these tests, which use polymerase chain reaction technology to search for modified DNA.

But the tests do not work with the refined products, such as oil or sugar, of some genetically modified organisms because they may contain no transgenic DNA, so figures for food containing these will depend on manufacturers' supplychain records .

Many retailers doubt that customers will buy food products labelled as genetically modified, and some refuse to stock them. Analysts are unsure whether the new rules will make any difference to consumer acceptance - or to the United States' complaint to the WTO.

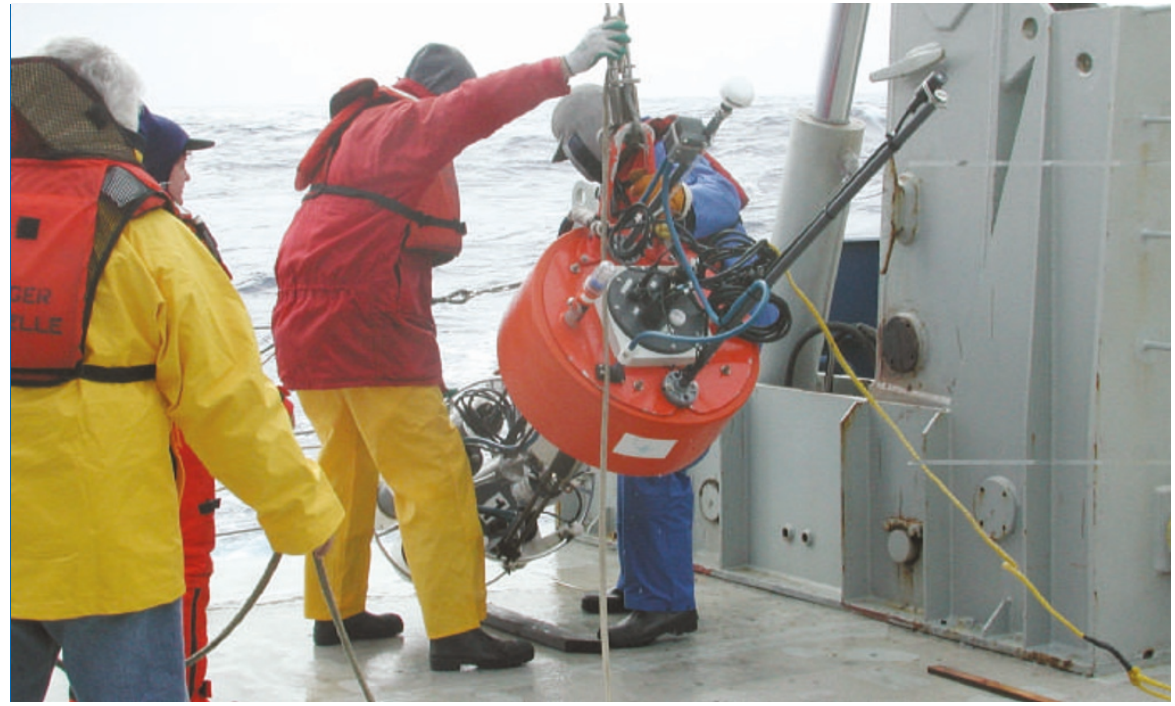

Haul aboard: fertilizing the sea causes biomass changes that could be used to combat global warming.

\title{
Iron seeding creates fleeting carbon sink in Southem Ocean
}

\section{Quirin Schiermeier, Munich}

Dumping iron sulphate in the ocean to cause plankton blooms might not seem an eco-friendly way to tackle global warming. But, according to the most extended trial of the technique so far, it could prove an effective one.

The outcome of the trial in the Southern Ocean, which surrounds Antarctica, was published in last week's Science. It suggests that each atom of iron added to the sea could pull between 10,000 and 100,000 atoms of carbon out of the atmosphere by encouraging plankton growth, which captures carbon and sinks it deep towards the ocean floor (see Science 304, 417; 2004).

If successfully scaled up, such 'iron fertilization' of the sea could make a real dent in the high level of carbon dioxide in the atmosphere, which is causing global warming. Some researchers estimate that using the technique in the Southern Ocean alone could absorb $15 \%$ of carbon dioxide build-up. But ecologists caution that the technique could damage marine ecosystems in ways yet to be established (see Nature 421, 109-110;2003).

A team of oceanographers from Californian marine research institutes dropped 1.7 tonnes of iron sulphate in the sea as part of the Southern Ocean Iron Experiment in 2002. They then used floating robots to measure the carbon flux - and found that lots of biomass was indeed created and consigned to the depths of the ocean, either as dead algae or fish excrement.

The findings have fuelled expectations that ocean fertilization could provide an environmentally friendly technique for reducing atmospheric carbon dioxide levels. "It is a worthy endeavour to mitigate future global warming," says Russ George, chief scientist of the California-based Planktos
Foundation, a non-profit organization supported by the Canadian rock star Neil Young, which promotes large-scale iron fertilization.

Iron is essential for plant growth. Most of it reaches the oceans through winds carrying eroded, iron-rich soils from dry areas on land. But changes in climate and vegetation since the end of the last glacial period are believed to have diminished the iron supply to the ocean - reducing the growth of plankton, which naturally absorbs carbon dioxide from the atmosphere. Advocates of the technique argue that they would simply be restoring iron in the ocean to its previous level.

Researchers are, nonetheless, investigating the ecological risks of iron fertilization. The most recent trial, conducted in the Southern Ocean last winter, was the European Iron Fertilization Experiment. A team led by Victor Smetacek, a biological oceanographer at the Alfred Wegener Institute in Bremerhaven, Germany, is expected to report later this year on ecosystem changes resulting from the experiment's creation of an artificial plankton bloom.

The relation of carbon cycles to marine processes is complex and the authors of the Science paper say the jury is still out on the technique."It would be premature to extrapolate our results to greater depths or larger areas," says James Bishop, lead author of the paper and an oceanographer at the Lawrence Berkeley National Laboratory in California.

But Smetacek believes that human intervention on a grand scale in ocean chemistry is likely to happen, sooner or later. "For the first time we have the tools for large-scale operations with ocean ecosystems," he says. "You will not do away with the mess that mankind has already made without using these tools. But we must face the challenge of using them responsibly." 